\title{
Topology optimisation of an aircraft nose-wheel fork for production in Ti6Al4V by the Aeroswift high-speed laser powder bed fusion machine
}

\author{
L F Monaheng $^{1 *}, \mathrm{~W}$ B du Preez ${ }^{2}, \mathrm{~N} \mathrm{Kotze}^{3}, \&$ M Vermeulen ${ }^{4}$ \\ ${ }^{1,2}$ Central University of Technology, Free State, Bloemfontein, South Africa \\ ${ }^{3,4}$ ADC Aeroswift, Wonderboom Airport, Pretoria, South Africa \\ *1monaheng@cut.ac.za
}

\begin{abstract}
$\underline{\text { Abstract }}$
Recent levels of structural integrity of components built in the Aeroswift high-speed laser powder bed fusion machine have led to the decision to produce a structural aircraft component through this technology. The Aeroswift machine is capable of building larger Ti6Al4V parts at a more rapid pace than current commercial laser metal powder bed fusion systems. As prototype component, the nose-wheel fork of the AHRLAC aircraft, which was conventionally machined in aluminum alloy 7050, was selected. This paper describes the design, topology optimisation and the manufacturing approach taken in this project.
\end{abstract}

Given the design space, loads, strength requirements and boundary conditions prescribed by the AHRLAC engineers, topology optimisation was performed on the nose-wheel fork to design a lightweight component for production in Ti6A14V. Different topology optimisation software suites were used, to establish their capabilities and fit-for-purpose features. The optimised design and percentage of weight saving are presented. An assessment based on the experience with the different software suites is offered.

Keywords: Topology optimisation, laser metal powder bed fusion, Titanium, nose-wheel fork. 


\section{Introduction}

AHRLAC (Advanced High Performance Reconnaissance Light Aircraft) is an unusual two-person cockpit pusher propeller plane, designed by engineers of the South African company Aerosud and manufactured in partnership between the Paramount Group and Aerosud. The AHRLAC company considers additive manufacturing (AM) as a technology fitting well in their manufacturing strategy [1] [2].

The Aeroswift high-speed laser powder bed fusion machine was designed to manufacture metallic parts from alloy powders, such as titanium and stainless steel [1] [3]. This system's large build volume of $2 \mathrm{~m} \times 0.6 \mathrm{~m} \times 0.6 \mathrm{~m}$ allows production of large parts, as well as large batches of small parts. Parts can be produced up to ten times faster than current commercial AM systems [1]. Recent levels of structural integrity of components built in the Aeroswift high-speed laser powder bed fusion machine have led to the decision to produce a structural aircraft component through this technology. As prototype component, the nose-wheel fork of the AHRLAC aircraft, which was conventionally machined in aluminum alloy 7050 , was selected.

Given the design space, loads, strength requirements and boundary conditions prescribed by the AHRLAC engineers, topology optimisation was performed on the nose-wheel fork to redesign a lightweight nose-wheel fork for production in Ti6Al4V. Different topology optimisation software suites were used to establish their capabilities and fit-for-purpose features.

Topology optimisation concentrates on the distribution of the material and structural connectivity in the design domain (space) [4]. The optimisation problem consists of the determination of the optimal distribution of a material in the design domain using a user defined objective function under the given constrains. Two main methods of topology optimisation are the gradient based and non-gradient based methods. In the non-gradient based method material is gradually removed from the structure using a sensitivity function to evolve towards an optimum [5]. For the gradient-based method a mathematical 
model (material-indicator function) is derived to calculate the sensitivities of the design variation [6]. The gradient-based optimisation method is used by the structural analysis software solvers MSC Nastran ${ }^{\circledR}$ and Altair OptiStruct ${ }^{\circledR}$. The gradient-based method Solid Isotropic with Material Penalisation (SIMP), which makes it easy to be implemented in the finite element analysis (FEA) framework, is often used [5]. The SIMP method implements the principle of a panelising density variable to converge to zero (void) or one (solid). In practice, low-density elements experience high levels of stress and are not removed from the design domain [7]. In this way the optimal shape (load path) is generated from the optimisation software.

The topology optimisation process has been applied successfully to minimise weight of aircraft parts. The applications include the design of inboard and outer fixed leading edge ribs, the fuselage door intercostal of the Airbus A380 aircraft, wing box rib and internal structure, spar structures under aeroelastic loads and aircraft structures flutter suppression [8] [9] [10]. It has been demonstrated that the use of topology optimisation for minimising the weight of aircraft parts reduce the fuel consumption and emission gasses, such as carbon dioxide and nitrogen oxide [11].

The combination of topology optimisation with AM of Ti6Al4V (ELI) could advance saving production cost and ensuring positive production in aviation industries [12]. However, this intriguing use of metal AM for production of aircraft structural parts presents great challenges to the designer. Unlike, the conventional method of producing aircraft structural parts, topology optimisation design for additive manufacturing (DfAM) practices are not sufficiently understood nor characterised for production of aircraft structural parts [13]. Therefore, there is a need to establish topology optimisation DfAM as a design tool for manufacturing of aircraft structural parts, with predictable structural performance using conventional design tools. This paper evaluated the capability and fit-for-purpose feature of the topology optimisation software used for the redesign of the AHRLAC nose-wheel fork.

\section{Material and experimentation}

\subsection{Material properties for AHRLAC nose-wheel fork}

The nose-wheel fork of the AHRLAC, which was conventionally machined from Al 7050 and is $8,23 \mathrm{~kg}$ in weight, was redesigned using topology optimisation software. The redesigned component would be manufactured in the Aeroswift machine from Ti6Al4V (ELI). In Table 1 the material properties used in the design process, as well as the properties of Al 7050 from which the existing nose-wheel fork is produced, are shown.

Table 1: Material properties used in the topology optimisation design.

\begin{tabular}{|l|c|c|c|c|}
\hline Materials & Elastic Modulus & Poisson's & Density & Yield \\
& (GPa) & ratio & $\mathbf{( k g / \mathbf { m } ^ { 3 } )}$ & Strength (MPa) \\
\hline Ti6A14V (ELI) & 110 & 0.31 & 4429 & 787 \\
\hline Al 7050 & 71 & 0.33 & 2830 & 450 \\
\hline
\end{tabular}

2.2. Topology optimisation with Altair SolidThinking Inspire ${ }^{\circledR}$ 
A computer-aided design (CAD) domain, derived from the CAD model of the machined nose-wheel fork shown in Figure 1(a) and (c) was created. The volume of the domain was made larger than the machined fork design to ensure design freedom. The bushes were separated from the design domain using the Inspire ${ }^{\circledR}$ partition tool. Additionally, the top contour and dimensions on the design domain, as well as the dimensions of the wheel, shock absorber and torque arm bushes, were kept the same as in the machined fork design, to ensure zero interference between the end-product and other parts of the aircraft. Figure 1(b) and (d) show the design domain with bushes. All loads and boundary conditions were set on the bushes.

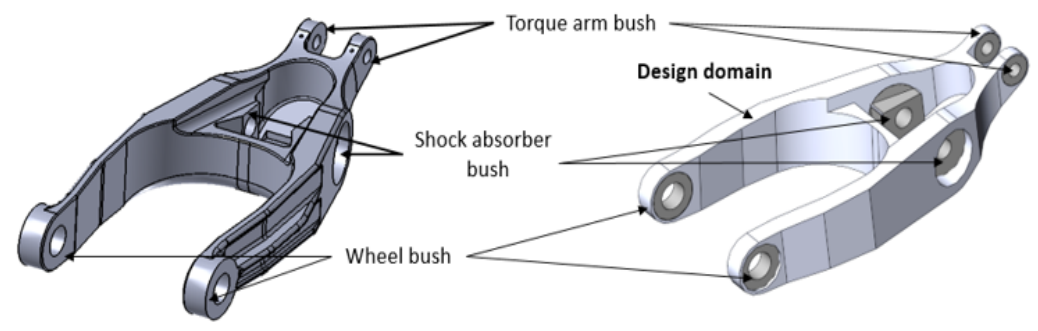

(a) Top view of the machined fork design.

(b) Top view of the design domain with bush.

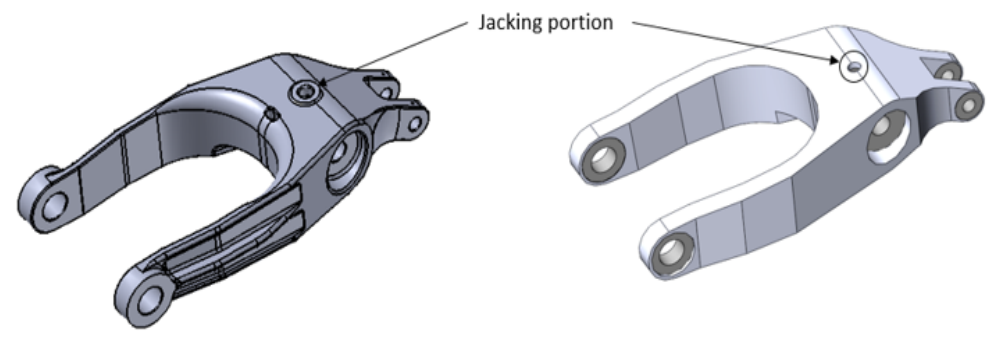

(c) Bottom view of the machined fork design. $\quad$ (d) Bottom view of the design domain with bush.

Figure 1: Nose-wheel fork design domain with bushes derived from the machined fork CAD model.

In Figure 2 the two main load configurations of the AHRLAC nose-wheel fork are illustrated. A total of 16 loads cases were provided by the AHRLAC engineers. Four of them were envelope calculated, while twelve conformed to Federal Aviation Regulations. For the maximum landing load case (Figure 2(a)) the fork experiences the loads through the wheel axle, while for the ground static case in Figure 2(b), the load acts on the fork through the tyre (Fz and Fy at the tyre radius). The ground static and maximum load cases are the highest loads experienced by the fork. Therefore, the optimisation was mainly done for these loads. 


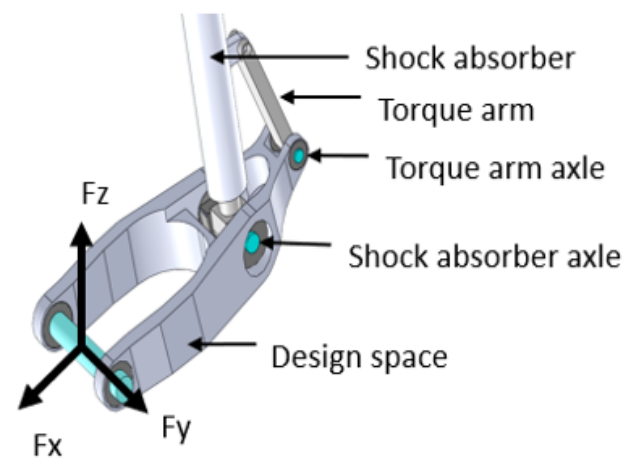

(a) Maximum landing load case

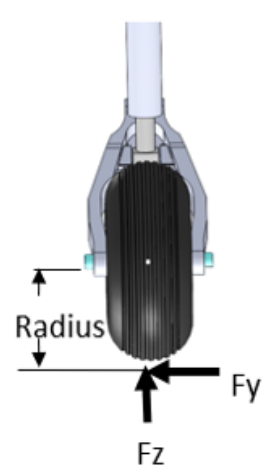

(b) Ground static load case

Figure 2: Configuration of the maximum landing (a) and ground static (b) load cases calculated by the AHRLAC engineers.

The mid node of the torque arm axle was restricted to translate only in the $Z$ direction. On the mid-point of the shock absorber axle, only rotation in the $\mathrm{Y}$ axis was allowed. Finally, the shape control, symmetric about the Z-X plane as illustrated in Figure 3, was set.

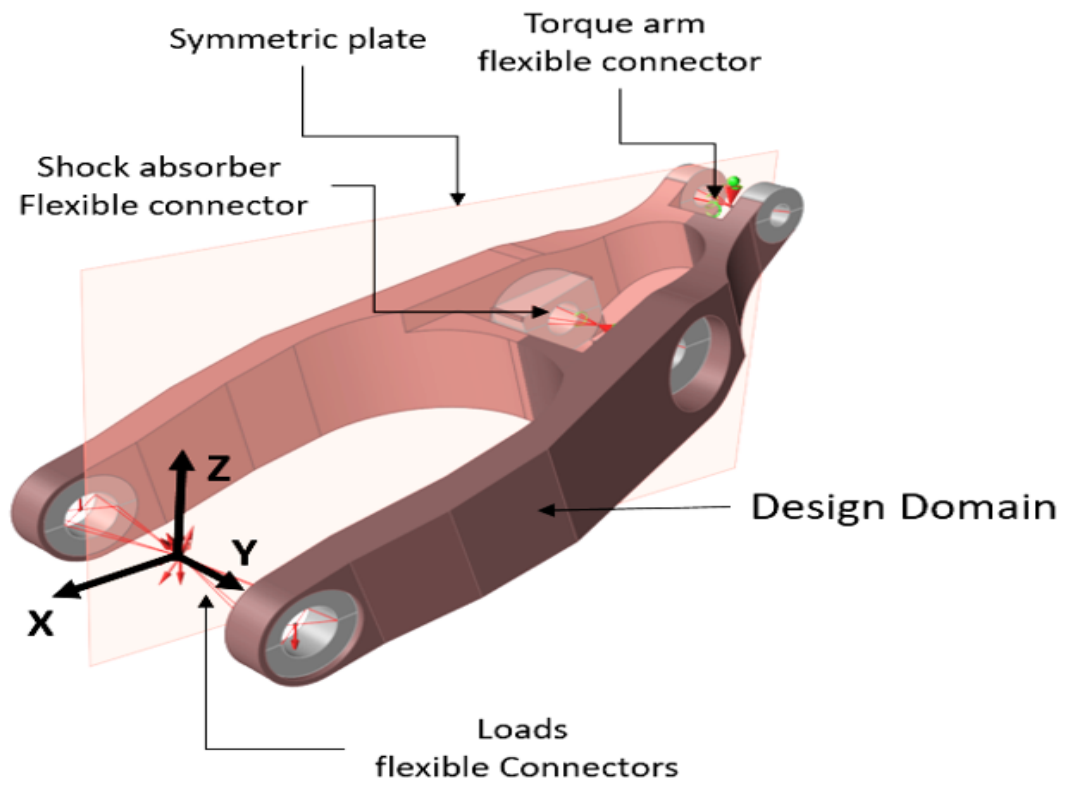

Figure 3: The connectors, all load cases, symmetric plane, and boundary conditions as set in the fork for topology optimisation. 
The Ti6Al4V (ELI) properties given in Table 1 were assigned on the bushes and design domain. Finally, the objective function was set as maximum stiffness mass target of $30 \%$ of the total design domain volume.

\subsection{Topology optimisation with MSC Patran ${ }^{\circledR}$}

Optimisation in the MSC Patran ${ }^{\circledR} 2018$ software, which uses Nastran ${ }^{\circledR} 2018.1$ as the solver, was based on the same design domain shown in Figure 1(b) and (d). For this process, the design domain was created using SolidWorks ${ }^{\mathbb{R}}$ because it is easier to use than Patran ${ }^{\circledR}$ for drawing a complex geometry. The design domain was first imported in the MSC Apex ${ }^{\circledR}$ software for hexahedral mesh generation. A mesh with global element length of $6 \mathrm{~mm}$ was generated and its quality was evaluated for invalid elements. The Ti6Al4V (ELI) material properties in Table 1 were set on the bush and design domain generated mesh before the database file (bdf) was exported and imported into the Patran ${ }^{\circledR}$ software. Beam elements were used to represent the wheel, shock absorber, and torque arm axles. At each end of the beam rigid body elements 3 (RBE 3 ) were used to transfer loads from the beam to the fork hex mesh CAD mode (or design domain with bush) as illustrated in Figure 3. Boundary conditions and loads were applied in the same way as was done in the Inspire ${ }^{\circledR}$ software. Finally, minimising the mass an objective function of a mass fraction of 0.3 was applied. Figure 4 illustrates the load, boundary conditions and mesh for the MSC Patran ${ }^{\circledR}$-Nastran ${ }^{\circledR}$ optimisation.
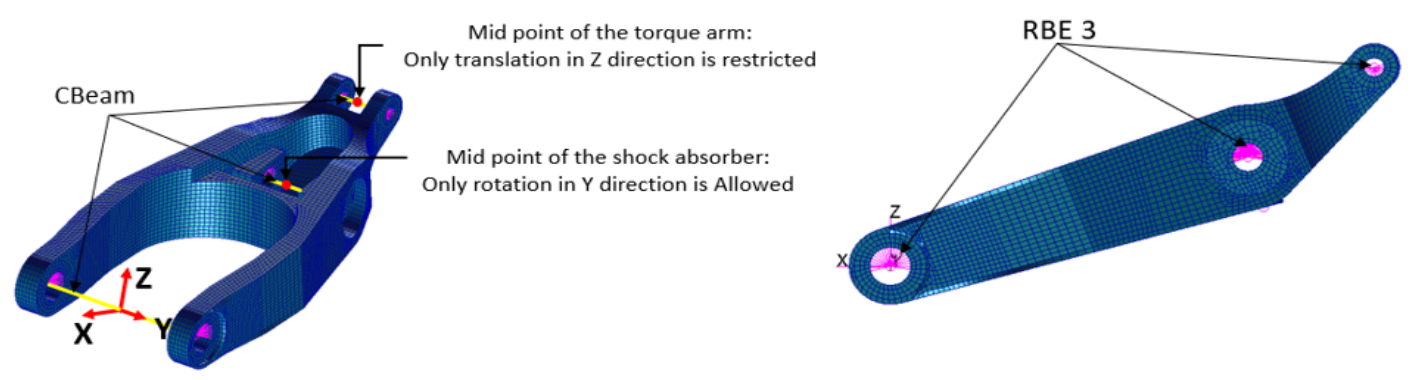

Figure 4: The load cases, boundary conditions, and mesh generated in the Patran ${ }^{\circledR}$ software, equivalent to that used with the Inspire ${ }^{\circledR}$ software.

\section{Results}

In Figure 5(a) and (b) the Altair SolidThinking Inspire ${ }^{\circledR}$ and MSC Patran ${ }^{\circledR}$-Nastran ${ }^{\circledR}$ topology optimisation results, respectively, are presented. The different views of the results are shown to demonstrate the similarity and the differences between the Altair and MSC topology optimisation software. These results illustrate the load path or the elements which experience more load. The top and bottom boundary elements carry more load and, therefore, were not removed from the design domain. On the other hand, the elements which experience low levels of stress were removed from the design space as seen for both the Altair and MSC optimisation results. 


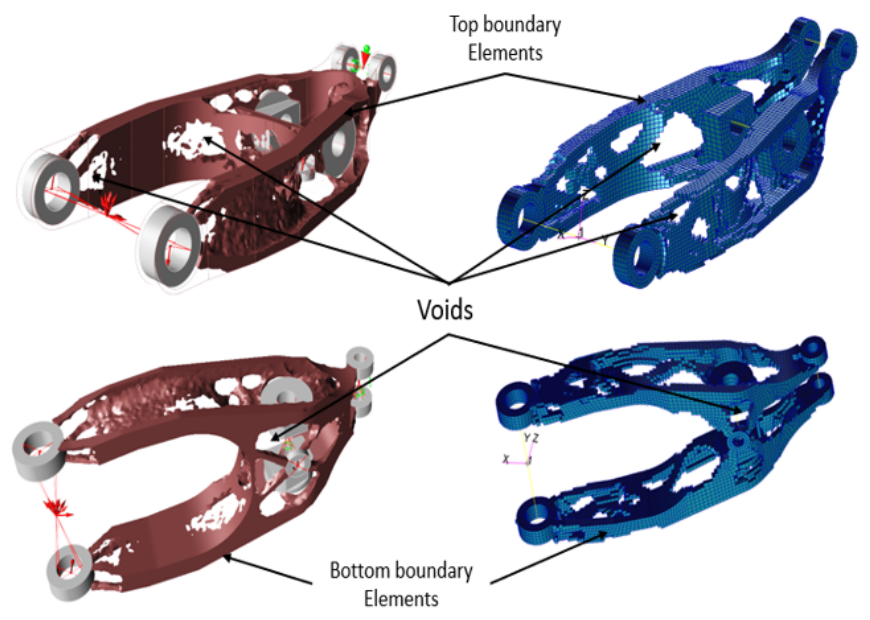

(a) Altair SolidThinking Inspire ${ }^{\circledR}$

(b) MSC Patran-Nastran

Figure 5: Views of the topology optimisation results. (a) Results from Inspire ${ }^{\circledR}$ software and the (b) from the Patran ${ }^{\circledR}$-Nastran ${ }^{\circledR}$ software.

Once the load path was determined, a smooth CAD model was generated to create the final design. The PolyNURB feature of the Altair SolidThinking Inspire ${ }^{\circledR}$ software was used to trace over the optimisation results with precision to create a free-form smooth geometry CAD model shown in Figure 6(a). The final design had a mass of $6.62 \mathrm{~kg}$. which is a $20 \%$ mass saving as compared to the machined fork design. Finally, the model was exported as STEP file for FEA. In MSC Patran $^{\circledR}$ the creation of geometry from elements is not automated, although not impossible, and the elements smoothing feature does not provide good quality, see Figure 6(b).
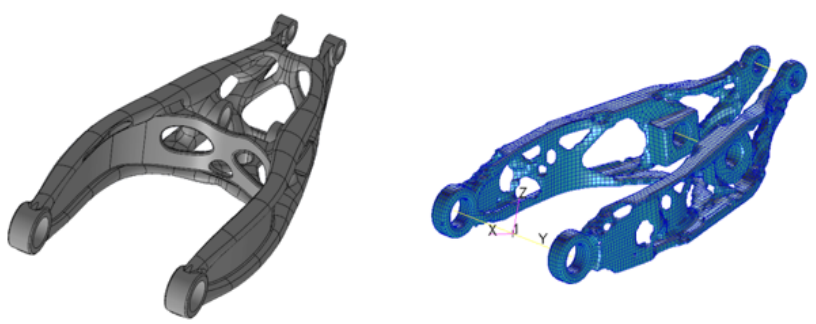

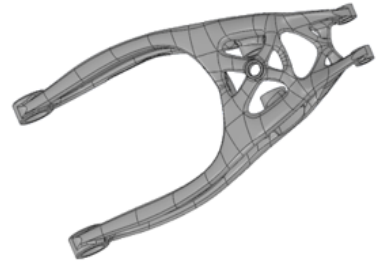

(a) Altair SolidThinking Inspire CAD model

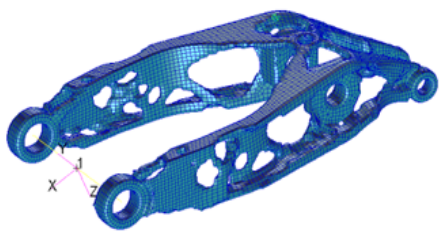

(b) MSC Patran smooth elements 
Figure 6: Views of the final design. (a) resulted from Altair SolidThinking Inspire ${ }^{\circledR}$ and (b) from the MSC Patran ${ }^{\circledR}$ -

$$
\text { Nastran }{ }^{\circledR} \text {. }
$$

The smooth optimal nose-wheel fork CAD model created from the Inspire ${ }^{\circledR}$ software was imported into the Patran ${ }^{\circledR}$ software for FEA purpose. A tetrahedral solid mesh was generated on the model with global element size of $10 \mathrm{~mm}$. The beam element, rigid body element 3, Ti6Al4V (ELI) properties together with the loads and boundary conditions were set on the final design CAD model in the same way as was done in the MSC topology optimisation. The Von Mises stress and maximum displacement experienced by the fork was computed for the maximum landing and ground static load cases. In Figure 7(a) and (b) the maximum Von Mises stress and the corresponding displacement are shown. Similarly, Figure 7(c) and (d) illustrate the stress experienced during the ground static load case with its respective displacement.

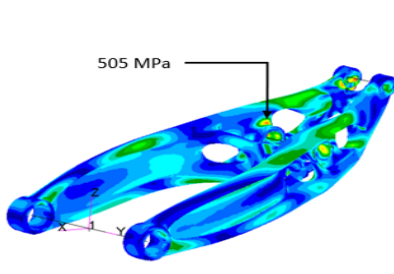

(a) Maximum load case Von Mises

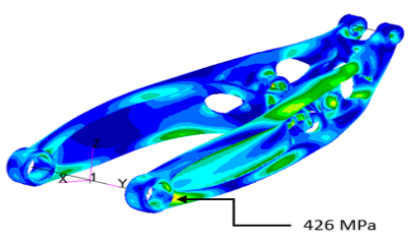

(c) Ground static case Von Mises
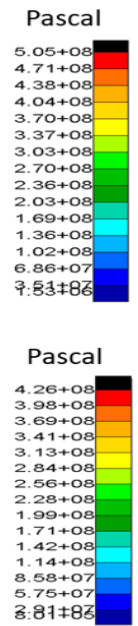
5. $75+07$
$3.87 \neq 83$

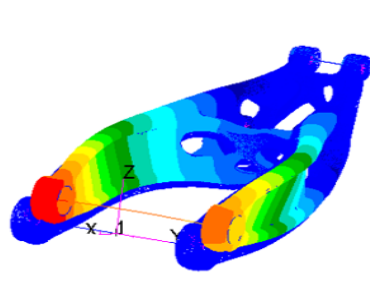

(b) Maximum load case displacements

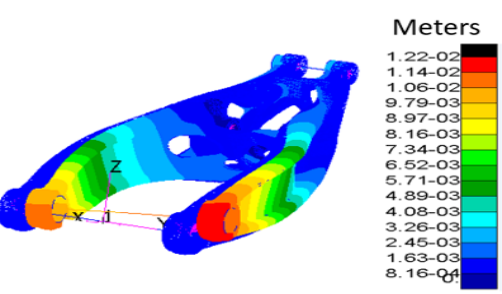

(d) Ground static case displacement
Meters

1.32-02

1. $14-02$

$1.05-02$
$9.65-03$

$9.65-03$
$8.77-03$
$7.90-03$

$7.90-03$

$6.14-03$

5. $26-03$

$4.39-03$
$3.51-03$

2.63-03

$1.75-03$
$8.77-84$ (1)

Figure 7: FEA results (a) and (b) for maximum load case and (c) and (d) for ground static load case.

The Von Mises stress calculated for the maximum and ground static load cases are $505 \mathrm{MPa}$ and $426 \mathrm{MPa}$, respectively. The maximum displacement for these same load cases are $13.2 \mathrm{~mm}$ and $12.2 \mathrm{~mm}$, respectively.

\section{Discussion}

\subsection{Assessment of the topology optimisation software fit-for-purpose feature}

Topology optimisation is possible with both Inspire ${ }^{\circledR}$ and Patran ${ }^{\circledR}$ software. At the no-design portion (bushes) no elements were removed to avoid introducing voids in the CAD model. However, elements were removed at portions of the design domain where the stresses were calculated to be low using FEA. The region of the design domain which experienced higher stress was kept solid. The connectivity of the solid portion in the design domain provide the load path. In this way weight is reduced from the design space by the topology optimisation software.

Different topology optimisation software suites from different vendors have different end user icons and optimisation approaches. In Table 2 the requirements of optimisation for the design of the landing gear fork are summarised for both software suites. 
Table 2: The requirements of topology optimisation for the design of the nose-wheel fork.

\begin{tabular}{|c|c|c|}
\hline $\begin{array}{l}\text { Topology optimisation } \\
\text { requirements }\end{array}$ & Altair SolidThinking Inspire ${ }^{\circledR}$ & MSC Patran $^{\circledR}$ \\
\hline 1. CAD model & $\begin{array}{l}\text { Large design domain is necessary. } \\
\text { Creating it from the existing model is } \\
\text { quick and fast using Inspire }{ }^{\circledR} \text { geometry } \\
\text { tools such as push-pull, simplifier, } \\
\text { partition. }\end{array}$ & $\begin{array}{l}\text { The design space creation from the } \\
\text { existing CAD model could be time } \\
\text { consuming for a complex geometry } \\
\text { such as the landing gear fork. It was } \\
\text { best done in SolidWorks }{ }^{\circledR} \text {. }\end{array}$ \\
\hline 2. Mesh & $\begin{array}{l}\text { Mesh generation is not user based. It is } \\
\text { robust and automatically applied on the } \\
\text { CAD model. }\end{array}$ & $\begin{array}{l}\text { For accurate results fine hexahedral } \\
\text { mesh is necessary. Generation of such } \\
\text { mesh requires decomposition of } \\
\text { complex CAD model in cuboids } \\
\text { and/or primitive shape, which can be } \\
\text { tedious, complex and difficult to } \\
\text { automate. MSC Apex }{ }^{\circledR} \text { software was } \\
\text { used for creation of hexahedral } \\
\text { mesh. }\end{array}$ \\
\hline 3. Material properties & $\begin{array}{l}\text { In the material library Ti6Al4V (ELI) is } \\
\text { available. Additionally, a new material } \\
\text { can be added in the library. }\end{array}$ & Material properties must be added in. \\
\hline $\begin{array}{l}\text { 4. Loads \& boundary } \\
\text { conditions }\end{array}$ & $\begin{array}{l}\text { Load and boundary conditions are auto } \\
\text { detected. For example, when applied on } \\
\text { the cylindrical face of the model, bearing } \\
\text { load is automatically suggested. } \\
\text { However, it is still up to the user to } \\
\text { define the desired loads and supports. } \\
\text { Finally, constraints are applied on the } \\
\text { non-design part of the model. }\end{array}$ & $\begin{array}{l}\text { The definition of the loads and } \\
\text { supports are required from the user. }\end{array}$ \\
\hline 5. Solver & $\begin{array}{l}\text { Optistruct }{ }^{\circledR} \text { software is integrated in } \\
\text { Inspire }{ }^{\circledR} \text { as the solver. It alters material } \\
\text { distribution to optimise the user defined } \\
\text { objective function under given } \\
\text { constraints using the gradient based } \\
\text { optimisation method. }\end{array}$ & $\begin{array}{l}\text { Nastran }{ }^{\circledR} \text { software is based on the } \\
\text { SIMP method for topology } \\
\text { optimisation in which a power-law is } \\
\text { used as penalty function. }\end{array}$ \\
\hline
\end{tabular}




\begin{tabular}{|c|c|c|}
\hline $\begin{array}{l}\text { 6. Topology optimisation } \\
\text { post-process }\end{array}$ & $\begin{array}{l}\text { Topology optimisation post-process } \\
\text { refers to conversion of the mesh, as } \\
\text { shown in Figure } 5 \text {, which is rough at } \\
\text { portions where elements with less stress } \\
\text { were removed, into a smooth solid CAD } \\
\text { model. With the PolyNURB }{ }^{\circledR} \text { function } \\
\text { available in Inspire }{ }^{\circledR} \text { software complex } \\
\text { shapes, which best represent the } \\
\text { optimisation results can be achieved. } \\
\text { Using Inspire }{ }^{\circledR} \text { in conjunction with CAD } \\
\text { software such as SolidWorks }{ }^{\circledR} \text { a best } \\
\text { design of the nose-wheel fork can be } \\
\text { repeatedly obtained as seen in Figure } \\
6(\text { a). } \\
\text { FEA is an essential post topology } \\
\text { optimisation to verify if the design can } \\
\text { handle all the loads. }\end{array}$ & $\begin{array}{l}\text { The conversion of elements into } \\
\text { CAD model, is not automated and the } \\
\text { mesh smoothing quality not good as } \\
\text { illustrated in Figure } 5(\text { b). However, } \\
\text { the model can be redrawn to resemble } \\
\text { the optimisation results illustrated. } \\
\text { For this complex geometry the } \\
\text { process is tedious, and mismatch is } \\
\text { highly possible. Several FEA } \\
\text { iterations will be necessary to verify } \\
\text { that the design of the nosewheel fork } \\
\text { can handle all the loads. }\end{array}$ \\
\hline 7. Data Storage & $\begin{array}{l}\text { Single file was generated during } \\
\text { topology optimisation. The size of the } \\
\text { file is } 5.5 \mathrm{Mb} \text {. }\end{array}$ & $\begin{array}{l}\text { Besides the database file, multiple } \\
\text { files, such as journal, master, session, } \\
\text { were generated. The total file size } \\
\text { amounts to } 5.5 \mathrm{~Gb} \text {. }\end{array}$ \\
\hline
\end{tabular}

\subsection{Success of the topology optimisation design for additive manufacturing}

The yield strength of parts built in the Aeroswift machine from Ti6Al4V is 787 MPa. The maximum Von Mises stress computed in both the maximum landing and ground static load cases is less that this yield strength. The total safety factor calculated was 1.6. The optimised final design was $20 \%$ less in weight than the machined fork design.

\section{Conclusions}

Topology optimisation design of the nose-wheel fork for production in Ti6Al4V (ELI) using the Aeroswift machine is possible with both the Altair SolidThinking Inspire ${ }^{\circledR}$ and MSC Patran ${ }^{\circledR}$-Nastran ${ }^{\circledR}$ software. However, the user features and processes are different. Inspire ${ }^{\circledR}$ has more user-friendly features than the MCS Patran ${ }^{\circledR}$-Nastran ${ }^{\circledR}$ software, making it the better and more time-effective tool for topology optimisation.

\section{Acknowledgements}

This research was supported and funded by the South African Department of Science and Technology through the Collaborative Program in Additive Manufacturing, Contract No.: CSIR-NLC-CPAM-15-MOA-CUT-01. 


\section{References}

[1] P. Middleton, African Fusion, Aeroswift as large-scale powder bed fusion AM system, Crown Publications. (2018) $20-21$.

[2] D. de Beer, W. du Preez, H. Greyling, F. Prinsloo, F. Sciammarella, N. Trollip, M. Vermeulen, with contributions from Terry Wohlers, A South African Additive Manufacturing Strategy, Department of Science and Technology, South African Additive Manufacturing Strategy. (2016).

[3] B. P. Conner, G.P. Manogharan, A.N. Martof, L.M. Rodomsky, C.M. Rodomsky, D.C. Jordan, J.W. Limperos, Making sense of 3-D printing creating a map of additive manufacturing products and services, Additive Manufacturing. 1-4 (2014) 64-76.

[4] K. Suzuki, N. Kikuchi, A Homogenization method for shape and topology optimization, Computer Methods in Applied Mechanics and Engineering. 94 (1991) 291-318.

[5] T. Earmme, M.M. Bernitsas, P.Y. Paoalambros, A.W. Troesch, D.G. Karr, Evolutionary Structural Optimization With Multiple Performance Constraints by Large Admissible Perturbations, University of Michigan. (2009).

[6] G. Kotucha, K. Hackl, Density gradiant based regularization of topology optimisation problems, PAMM. Proceeding of Appplied Mechanics. 5 (2005) 423-424.

[7] R. Picelli, S. Townsend, C. Brampton, J. Norato, and H. A. Kim, Stress-based shape and topology optimization with the level set method, Computer. Methods in Applied Mechanics and Engineering. 329 (2018) 1-23.

[8] D. J. Munk, G. A. Vio, J. E. Cooper, Topology Optimisation of Representative Aircraft Wing Geometries With an Experimental Validation, International Forum Aeroelasticity and Structural dynamics IFASD. (2017) 1-12.

[9] D. J. Munk, G. A. Vio, J. E. Cooper. Topology optimisation of aircraft structures for flutter suppression, Proceedings of the International Conference on Noise and Vibration Engineering ISMA. (2016) 3111-3126.

[10] B. K. Stanford and P. D. Dunning, Optimal Topology of Aircraft Rib and Spar Structures under Aeroelastic Loads, Journal of Aircraft. 52 (2015) 1-23.

[11] S. Rao, J Kiran, S. Chandra, J.V. Kamesh, M.A. Padmanabhan, Topology Optimization of Aircraft Wing CEUR Workshop Proceeding. 1542 (2015) 33-36.

[12] V. Bashkite, T. Karaulova, and O. Starodubtseva, Framework for innovation-oriented product end-of-life strategies development, Procedia Engineering. 69 (2014) 526-535.

[13] P. A. Kobryn, N. R. Ontko, L. P. Perkins, and J. S. Tiley, Additive Manufacturing of Aerospace Alloys for Aircraft Structures, AVT-139 Specialists' Meeting in Amsterdam. 139 (2006) 1-14. 